\title{
Karakterisasi Struktur Mikro dan Kekerasan Hasil Pengelasan Shield Metal Arc Welding (SMAW) dan Friction Stir Welding (FSW) Baja St 37
}

\author{
Sulardjaka*, Deni Fajar Fitriyana, Norman Iskandar, D. I. Mubarok \\ Departemen Teknik Mesin, Fakultas Teknik, Universitas Diponegoro \\ Jl. Prof. Sudharto, SH. Tembalang, Semarang \\ *Email: sulardjaka@undip.ac.id
}

\begin{abstract}
Microhardness distribution and microstructure of St 37 of Shield Metal Arc Welding (SMAW) and Friction Stir Welding (FSW) have been investigated. SMAW processes were done in $0.2 \mathrm{~cm} / \mathrm{s}, 0.4 \mathrm{~cm} / \mathrm{s}$ and $0.7 \mathrm{~cm} / \mathrm{s}$ with welding current variation of: $60 \mathrm{~A}, 80 \mathrm{~A}$ and $100 \mathrm{~A}$. FSW was done in variation of rotation tool of shoulder 1500 and $2000 \mathrm{rpm}$. Microhardness Vickers tests have been conducted on each specimen variation. The results show that the SMAW welding process highest of average hardness is about $284.9 \mathrm{HV}$ on $0.7 \mathrm{~cm} / \mathrm{s}$ welding speed and $60 \mathrm{~A}$ welding current. Higest average hardness of FSW is about $240.7 \mathrm{HV}$ at $1500 \mathrm{rpm}$ tools rotation. Lower of current and higher welding speed on SMAW and lower rotation of pin on FSW give higher hardness of welded joint.
\end{abstract}

Keyword: Friction Stir Welding (FSW), hardness, Shield Metal Arc Welding (SMAW), microstructure

\begin{abstract}
Abstrak
Penelitian ini bertujuan untuk meneliti distribusi kekerasan mikro pada hasil pengelasan baja St 37 dengan metode pengelasan Shield Metal Arc Welding (SMAW) dan Friction Stir Welding (FSW). Pengelasan SMAW dilakukan dengan kecepatan pengelasan: $0,2 \mathrm{~cm} / \mathrm{det}, 0,4 \mathrm{~cm} / \mathrm{det}$ dan $0,7 \mathrm{~cm} / \mathrm{det}$ dengan variasi arus pengelasan 60 A, 80 A dan 100 A. Pengelasan dengan FSW dilakukan dengan variasi kecepatan rotasi pin $1500 \mathrm{rpm}$ dan $2000 \mathrm{rpm}$ dengan kecepatan pengelasan $4 \mathrm{~cm} / \mathrm{menit}$. Pengujian kekerasan mikro dilakukan dengan metode microhardness Vicker. Hasil penelitian menunjukkan bahwa kekerasan rata - rata terbesar spesimen pengelasan SMAW terdapat pada arus 60 A kecepatan pengelasan $0,7 \mathrm{~mm} /$ detik bernilai $284,9 \mathrm{HV}$. Hasil kekerasan rata - rata terbesar spesimen pengelasan FSW terdapat pada kecepatan putar pin $1500 \mathrm{rpm}$ bernilai 240,7 HV. Semakin rendah arus listrik yang digunakan, semakin tinggi kecepatan pengelasan, dan semakin rendah kecepatan putar pin maka akan semakin besar nilai kekerasannya.
\end{abstract}

Kata kunci: Friction Stir Welding (FSW), Kekerasan, Shield Metal Arc Welding (SMAW), Struktur Mikro

\section{Pendahuluan}

Pengelasan adalah proses penyambungan logam atau non logam yang dilakukan dengan memanaskan material yang disambung hingga temperatur las yang dilakukan secara, dengan atau tanpa tekanan, hanya dengan tekanan atau dengan tanpa menggunakan pengisi (filler) [1]. Metode pengelasan merupakan metode penyambungan yang banyak dipakai dalam aplikasi karena metode ini ekonomis, ringan, cepat dan memiliki fleksibilitas dalam desain [2,3].

Metode pengelasan yang banyak digunakan adalah metode pengelasan fusi. Metode fusi dilakukan dengan melelehkan sebagian logam, sehingga saat logam cair tersebut membeku, kedua logam bisa tersambung. Metode pengelasan dengan metode fusi memiliki kelemahan, yaitu: terbentuknya tegangan sisa, adanya distorsi, atau timbulnya retakan atau void pada sambungan [3]. Untuk mengatasi kelemahan pada pengelasan fusi, pada tahun 1996 dikembangkan metode friction stir welding (FSW). Proses pengelasan dengan FSW terjadi pada kondisi padat (solid state joining) [4]. Temperatur pengelasan FSW tidak terlalu tinggi, sehingga tegangan sisa yang terbentuk dan distorsi akibat panas juga rendah. Pengelasan dengan metode FSW membutuhkan energi yang lebih sedikit, jika dibandingkan dengan pengelasan metode penegelasan fusi (gas metal arc welding) [5].

Pada pengelasan SMAW, penyetelan kuat arus pengelasan akan mempengaruhi hasil las. Bila kuat arus yang digunakan terlalu rendah akan menyebabkan sukarnya penyalaan busur listrik. Busur listrik yang terjadi tidak stabil. Panas yang terjadi tidak cukup untuk melelehkan elektroda dan bahan dasar sehingga hasilnya merupakan manik manik las yang kecil dan tidak rata serta penembusan kurang dalam [6]. Kecepatan pengelasan juga berpengaruh pada nilai kekerasan dan struktur mikro dari spesimen uji. Kecepatan las yang tinggi dapat menyebabkan kurangnya penetrasi, berkurangnya kekuatan sambungan dan mengakibatkan masukan panas yang diterima per satuan panjang akan menjadi lebih kecil. Hal ini dapat berdampak pada pendinginan yang cepat sehingga dapat memperkeras daerah yang terpengaruh panas [6-9]. Kecepatan putaran tool shoulder pada pengelasan FSW mempengaruhi kekuatan tarik hasil pengelasan [10-11]. 
Penelitian ini meneliti distribusi kekerasan mikro pada hasil pengelasan SMAW dan FSW baja St 37. Pengelasan SMAW dilakukan dengan variasi kecepatan pengelasan dan arus pengelasan. Pengelasan FSW dilakukan dengan variasi kecepatan putaran $1500 \mathrm{rpm}$ dan $2000 \mathrm{rpm}$ dengan kecepatan pengelasan $4 \mathrm{~cm} / \mathrm{menit}$.

\section{Material dan Metode Penelitian}

Material yang digunakan dalam penelitian adalah plat baja St 37. Ukuran benda kerja pengelasan adalah panjang $250 \mathrm{~mm}$, lebar $50 \mathrm{~mm}$, dan tebal $3 \mathrm{~mm}$. Elektroda yang digunakan untuk pengelasan SMAW berjenis E7016 dengan diameter 2,4 mm. Tool shoulder yang digunakan untuk pengelasan FSW terbuat dari bahan tungsten karbida.

Pengelasan SMAW dilakukan dengan variasi arus pengelasan yang digunakan adalah 60 A, 80 A, dan 100 A. Kecepatan pengelasan SMAW bervariasi: 0,2 mm/det, 0,4 mm/det dan 0,7 mm/det. Pengelasan FSW dilakukan dengan menggunakan mesin CNC milling. Shoulder yang dipakai terbuat dari tungsten karbida dengan ukuran 50 mm x 16 mm. Pin shoulder berbentuk kerucut tinggi 2,8 mm, diameter pangkal pin sebesar $6 \mathrm{~mm}$ dan diameter ujung 2. Proses pengelasan FSW dilakukan dengan variasi kecepatan rotasi pengelasan sebesar $1500 \mathrm{rpm}$ dan $2000 \mathrm{rpm}$. Jenis sambungan pengelasan adalah sambungan tumpul (butt joint). Pengujian kekerasan mikro yang dilakukan adalah kekerasan mikro Vickers dengan metode pengujian mengacu pada standar ASTM E92.

\section{Hasil dan Pembahasan}

Tabel 1 menunjukkan besarnya masukan panas (heat input) pada proses pengelasan. Heat input ini proses pengelasan SMAW, merupakan hasil dari perhitungan berdasarkan persamaan 1 [12].

$$
q=\frac{V . I . \eta .60}{s .1000}
$$

dimana:

$$
\begin{array}{ll}
q & : \text { masukan panas }(\mathrm{kJ} / \mathrm{mm}) \\
V & : \text { tegangan }(\text { Volt }) \\
I & : \text { arus (ampere) } \\
\eta & : \text { efisiensi } \\
s & : \text { kecepatan pengelasan }(\mathrm{mm} / \text { menit })
\end{array}
$$

Tabel 1. Nilai heat input proses pengelasan SMAW

\begin{tabular}{cccc} 
No. Spesimen & Arus listrik (A) & Kecepatan pengelasan $(\mathbf{m m} / \mathbf{d e t i k})$ & H $(\mathbf{k J} / \mathbf{m m})$ \\
\hline 1. & 60 & 7 & 1,97 \\
2. & 60 & 4 & 3,45 \\
3. & 60 & 2 & 6,90 \\
4. & 80 & 7 & 2,62 \\
5. & 80 & 4 & 4,60 \\
6. & 80 & 2 & 9,20 \\
7. & 100 & 7 & 3,28 \\
8. & 100 & 4 & 5,75 \\
9. & 100 & 2 & 11,50 \\
\hline
\end{tabular}

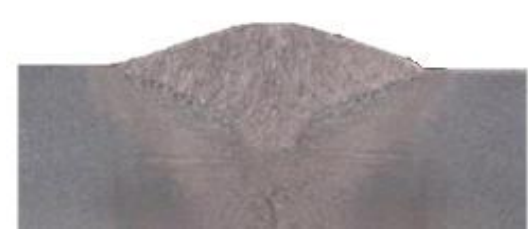

(a)

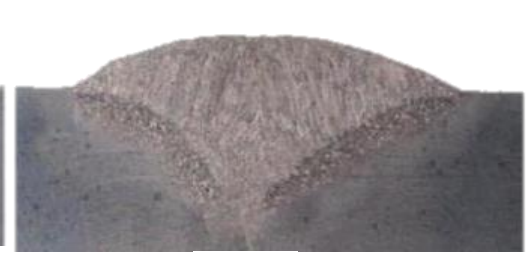

(b)

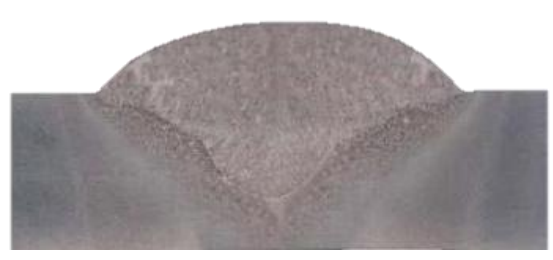

(c)

Gambar 1. Struktur makro tanpa perbesaran pada spesimen dengan masukan panas, (a) 1,97 kJ/mm (b) 4,60 $\mathrm{kJ} / \mathrm{mm}$ (c) $11,50 \mathrm{~kJ} / \mathrm{mm}$

Hasil perhitungan nilai masukan panas (Tabel 1) menunjukkan bahwa pengelasan dengan arus listrik $60 \mathrm{~A}$ dan kecepatan pengelasan $0,7 \mathrm{~cm} /$ detik ( $7 \mathrm{~mm} /$ detik) memiliki masukan panas yang kecil. Spesimen dengan arus listrik 100 A dan kecepatan pengelasan $0,2 \mathrm{~cm} /$ detik $(2 \mathrm{~mm} /$ detik) memiliki masukan panas terbesar yaitu $11,5 \mathrm{~kJ} / \mathrm{mm}$. Terdapat dua spesimen yang memiliki heat input yang hampir sama yaitu spesimen dengan arus listrik 60 A kecepatan pengelasan $0,4 \mathrm{~cm} /$ detik ( $4 \mathrm{~mm} /$ detik) dan spesimen dengan arus listrik $100 \mathrm{~A}$ kecepatan pengelasan $0,7 \mathrm{~cm} / \mathrm{detik}(7$ $\mathrm{mm}$ /detik). Foto makro hasil pengelasan dengan 3 parameter masukan panas yang berbeda ditunjukkan pada Gambar 1 . 
Foto tersebut menunjukkan nilai masukan panas terkecil yaitu 1,97 kJ/mm, menghasilkan luasan zona pengelasan terkecil dengan penetrasi yang dangkal (Gambar 1.a). Semakin besar masukan panas, luasan daerah las akan semakin besar dan kedalaman penetrasi juga akan semakin dalam $[6,7,13]$.

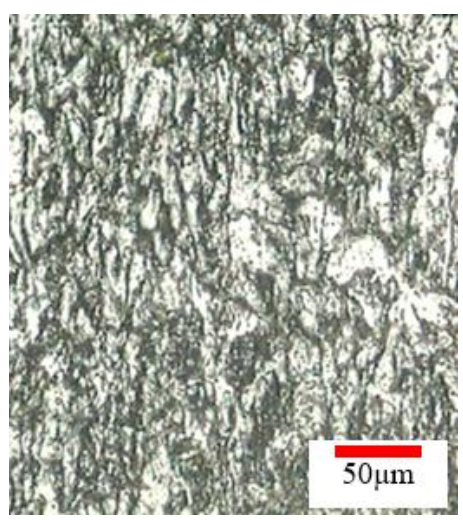

(a)

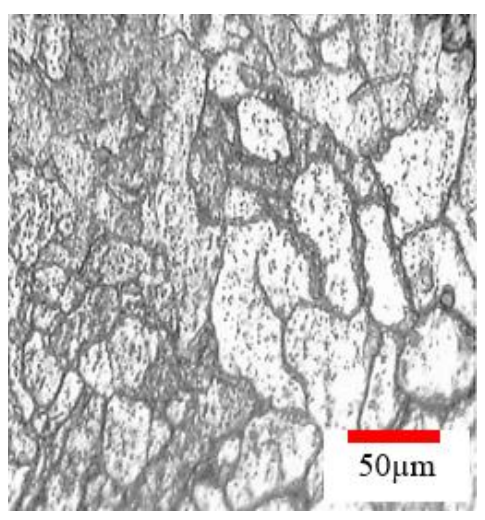

(b)

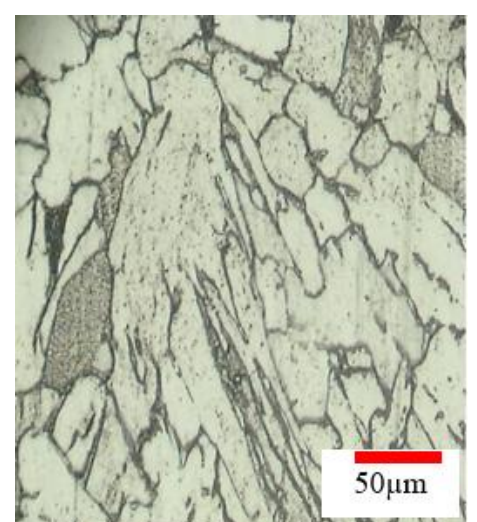

(c)

Gambar 2. Struktur mikro daerah HAZ pada hasil pengelasan SMAW dengan masukan panas, (a) 1,97 kJ/mm (b) 4,60 $\mathrm{kJ} / \mathrm{mm}(\mathrm{c}) 11,50 \mathrm{~kJ} / \mathrm{mm}$

Gambar 2 menunjukkan struktur mikro daerah HAZ pada hasil pengelasan SMAW dengan masukan panas (a) 1,97 $\mathrm{kJ} / \mathrm{mm}$ (b) $4,60 \mathrm{~kJ} / \mathrm{mm}$ (c) $11,50 \mathrm{~kJ} / \mathrm{mm}$. Heat input berperan besar dalam perubahan struktur mikro pada daerah terpengaruh panas (HAZ). Foto pada Gambar 2 menunjukkan, semakin tinggi masukan panas pengelasan, maka semakin ukuran butir daerah HAZ juga semakin besar. Struktur mikro daerah HAZ hasil pengelasan SMAW, dipengaruhi oleh arus pengelasan dan kecepatan pengelasan. Arus listrik pengelasan berpengaruh langsung pada penetrasi logam las, bentuk manik las, dan dilusi atau pencampuran. Arus las makin besar dapat memperdalam penetrasi logam las dan juga memperlebar HAZ $[12,14]$.

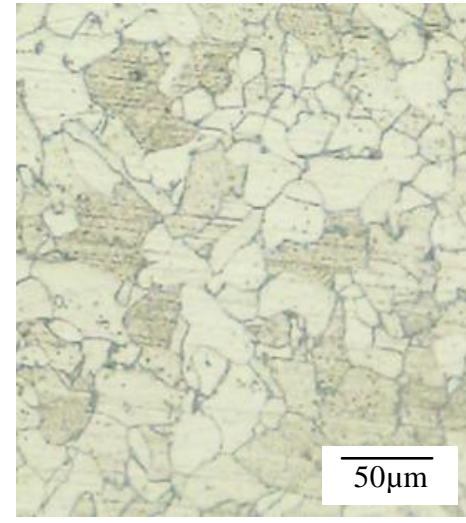

(a)

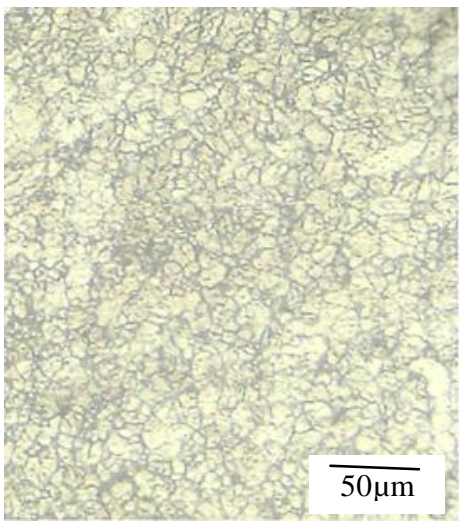

(b)

Gambar 3. Struktur mikro HAZ hasil pengelasan FSW, (a) kecepatan putar tool 2000 rpm (b) kecepatan putar tool $1500 \mathrm{rpm}$

Struktur mikro daerah HAZ hasil pengelasan FSW ditunjukkan pada Gambar 3. Pada FSW putaran shouldered pin tool berpengaruh pada suhu yang dihasilkan, semakin cepat berotasi maka semakin meningkat pula suhu pengelasan. Akibat dari meningkatnya suhu pengelasan, maka semakin meningkat pula pertumbuhan butir dan persebaran material pada daerah pengelasan [10].

Grafik hasil uji kekerasan pada pengelasan SMAW dengan kecepatan pengelasan $0,7 \mathrm{~cm} / \mathrm{detik}, 0,4 \mathrm{~cm} / \mathrm{detik}$, dan $0,2 \mathrm{~cm} /$ detik secara berurutan ditunjukkan pada Gambar 4, Gambar 5 dan Gambar 6. Ketiga grafik merupakan perbandingan nilai kekerasan spesimen SMAW dengan variasi arus listrik. Gambar 4 mempunyai nilai kekerasan tertinggi pada spesimen 60 A kecepatan pengelasan $0,7 \mathrm{~cm} /$ detik. Nilai kekerasan rata - rata pada daerah logam lasnya adalah 284,9 HV dan nilai kekerasan rata - rata pada daerah HAZ nya adalah 267,8 HV. Gambar 5 mempunyai nilai kekerasan tertinggi pada spesimen 60 A kecepatan pengelasan $0,4 \mathrm{~cm} /$ detik. Nilai kekerasan rata - rata pada daerah logam lasnya adalah $266 \mathrm{HV}$ dan nilai kekerasan rata - rata pada daerah HAZ nya adalah 252,1 HV. Gambar 6 mempunyai nilai kekerasan tertinggi pada spesimen 60 A kecepatan pengelasan $0,2 \mathrm{~cm} /$ detik. Nilai kekerasan rata - rata pada daerah weld metal-nya adalah 252,8 HV dan nilai kekerasan rata - rata pada daerah HAZ nya adalah $241,3 \mathrm{HV}$. Semakin kecil arus listrik yang digunakan maka heat input kecil namun laju pendinginan dari spesimen tersebut semakin cepat sehingga dapat membuat nilai kekerasan daerah logam las maupun HAZ semakin besar [14]. 


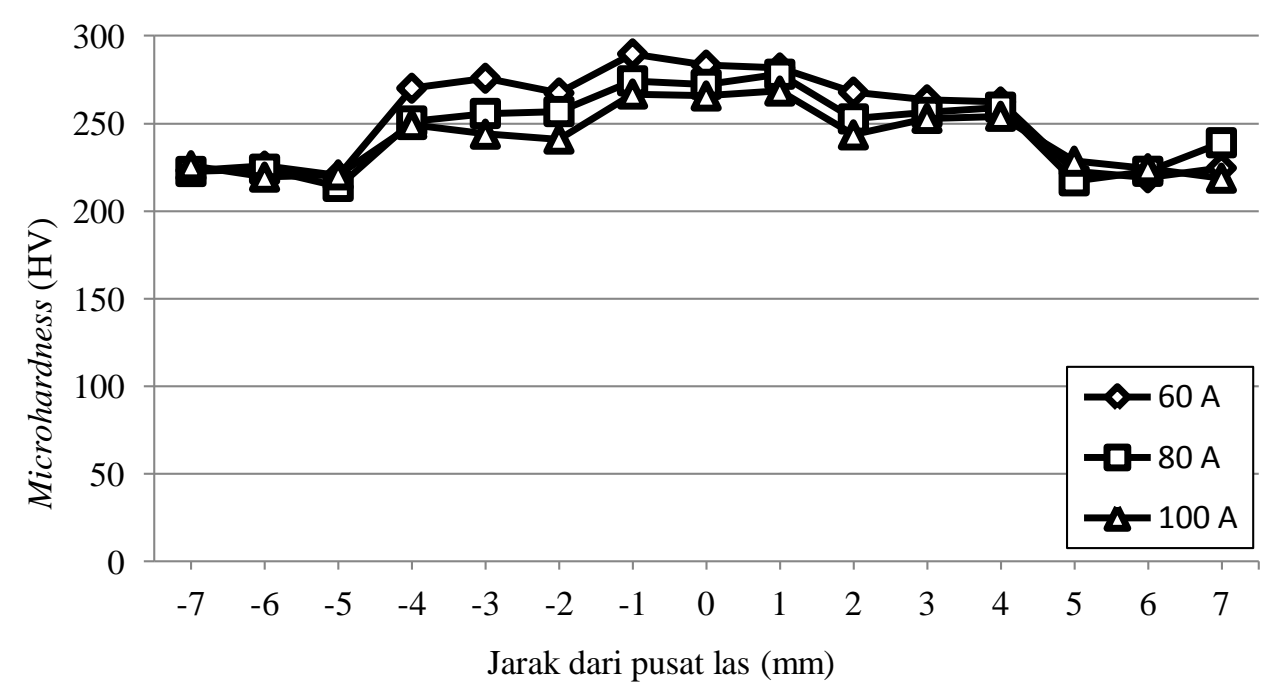

Gambar 4. Grafik nilai kekerasan pada pengelasan SMAW dengan kecepatan pengelasan $0,7 \mathrm{~cm} /$ detik

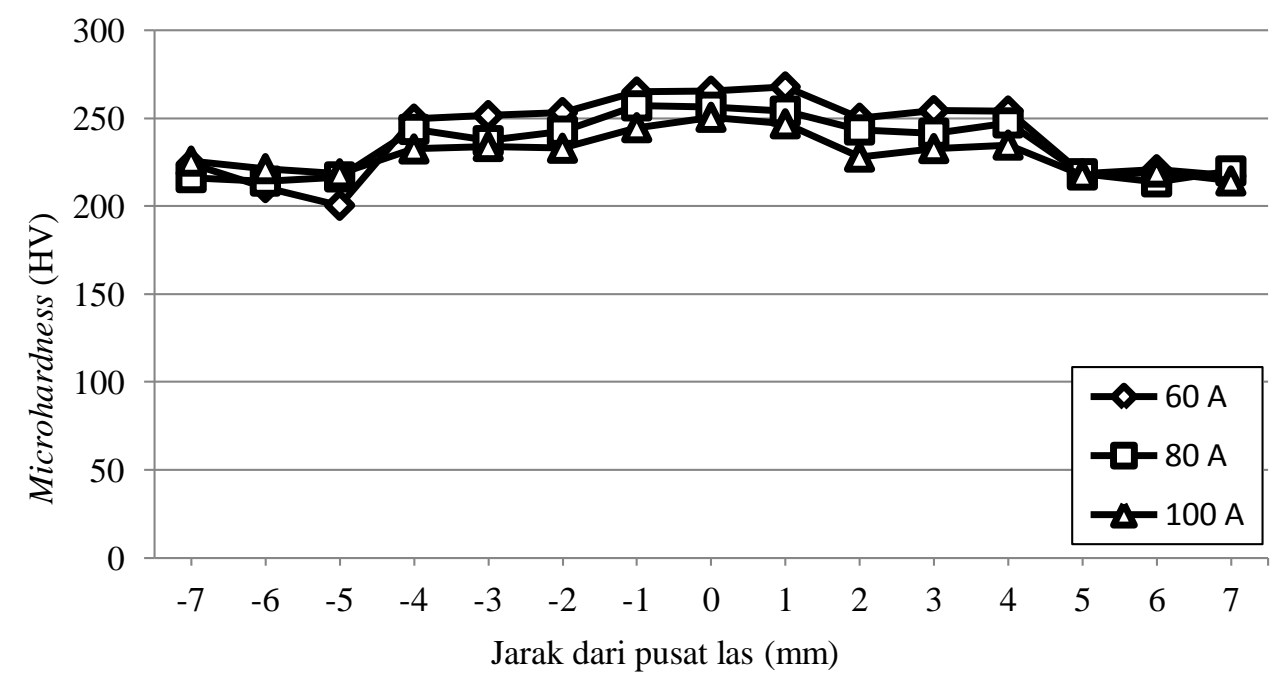

Gambar 5. Grafik nilai kekerasan pada pengelasan SMAW dengan kecepatan pengelasan $0,4 \mathrm{~cm} /$ detik

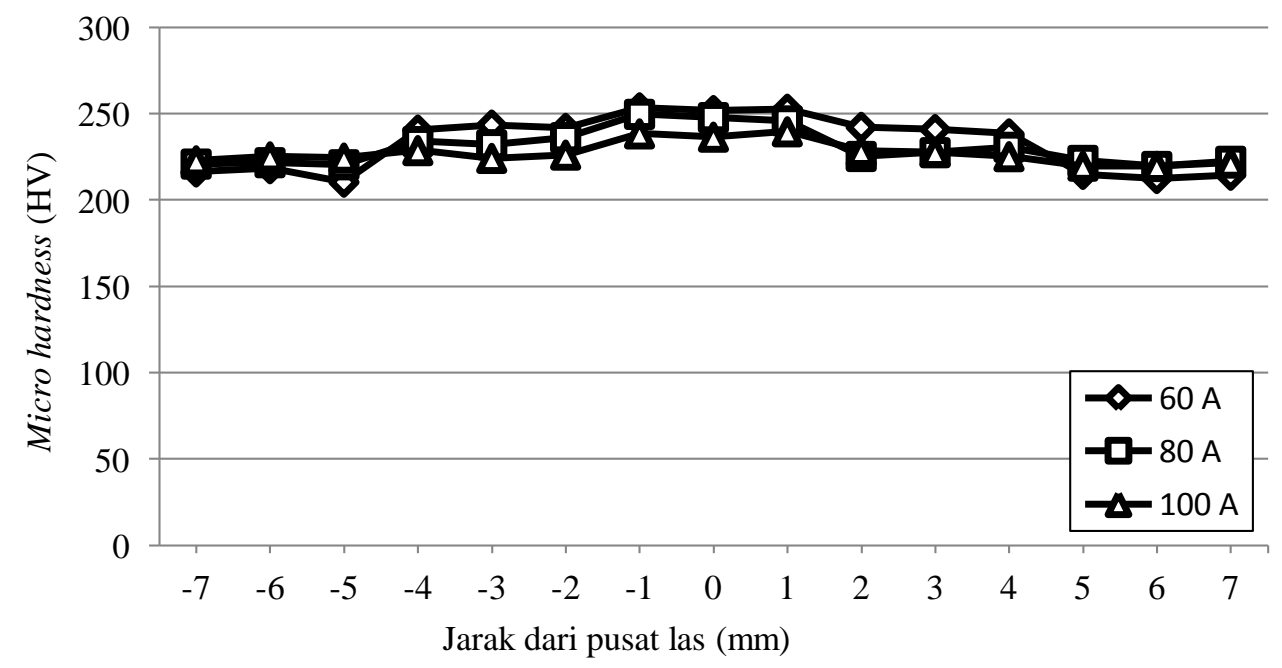

Gambar 6. Grafik nilai kekerasan pada pengelasan SMAW dengan kecepatan pengelasan $0,2 \mathrm{~cm} / \mathrm{detik}$

Gambar 7 menunjukkan grafik distrbusi kekerasan pada hasil pengelasan FSW. Grafik tersebut menunjukkan nilai kekerasan dari spesimen FSW dengan kecepatan putar pin 1500 rpm dan 2000 rpm. Pada kecepatan pin 1500 rpm, nilai kekerasan logam lasnya (240,7 HV) lebih tinggi dibanding 2000 rpm karena cooling rate nya lebih besar dari $2000 \mathrm{rpm}$ 
sehingga nilai kekerasanya semakin besar. Nilai kekerasan HAZ pada kecepatan pin 1500 rpm lebih tinggi daripada 2000 rpm dengan nilai kekerasan 165,9 HV. Nilai kekerasan logam las spesimen FSW ini hampir sama dengan nilai kekerasan pada spesimen SMAW dengan arus listrik $100 \mathrm{~A}$ dan kecepatan pengelasan 0,2 cm/detik. Nilai kekerasan spesimen SMAW rata - rata mempunyai nilai kekerasan yang lebih tinggi dibandingkan dengan spesimen FSW. Hal tersebut disebabkan karena beberapa faktor berupa adanya perbedaan dalam metode pengelasan dan panas yang diterima (heat input) sehingga memiliki struktur mikro yang berbeda pula [10].

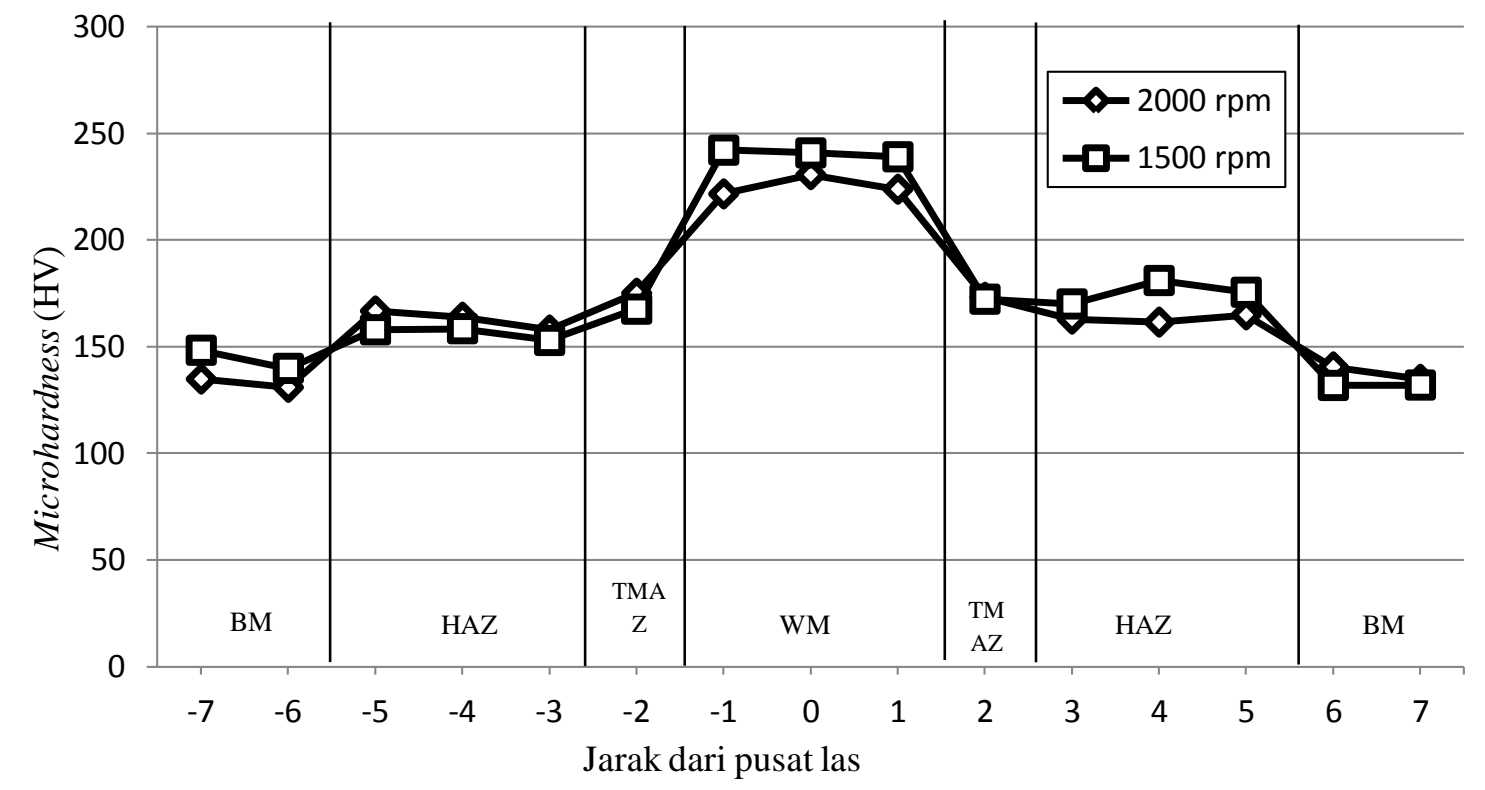

Gambar 7. Grafik nilai kekerasan pada pengelasan FSW

\section{Kesimpulan}

Pada metode SMAW, arus las semakin besar dapat memperdalam penetrasi logam las dan memperlebar HAZ dan weld metal. Kecepatan pengelasan semakin cepat dapat memperkecil ukuran butir pada HAZ dan weld metal. Semakin tinggi arus listrik maka semakin kecil nilai kekerasan baja St 37. Semakin tinggi kecepatan pengelasan maka semakin besar nilai kekerasan baja St 37. Pada metode FSW, struktur mikro daerah HAZ dan logam las terbesar pada kecepatan pin 2000. Struktur mikro daerah HAZ dan logam las pada pengelasan FSW terlihat lebih rapi dibandingkan dengan pengelasan SMAW. Semakin tinggi kecepatan putar pin maka semakin kecil nilai kekerasan baja St 37. Pengelasan SMAW dengan arus 60 A dan 80 A mempunyai nilai kekerasan logam las dan HAZ lebih tinggi dibandingkan dengan spesimen pengelasan FSW dengan kecepatan putaran pin 1500 rpm dan $2000 \mathrm{rpm}$.

\section{Referensi}

[1] American Society for Metal Handbook, 1993, "Welding Brazing and Soldering".

[2] Armentani, E., Esposito, R., Sepe, R. (2007). The effect of thermal properties and weld efficiency on residual stresses in welding, Journal of Achievements in Materials and Manufacturing Engineering, Vol. 20, No. 1-2, 319322.

[3] Cary, Howard B., 1989, Modern Welding Technologi, Prentice Hall, New Jersey.

[4] Dawes, C.T. dan Thomas, W.M., 1996, Friction Stir Process Weld Aluminum Alloy: A New Friction Welding Technique Allows Easy Welding of Normally Difficult - to - Joint Materials, Welding Journal 75: 41.

[5] Shrivastava, A., Manuela Krones, M., dan Pfefferkorn, F.E., 2015, Comparison of energy consumption and environmental impact of friction stir welding and gas metal arc welding for aluminum, CIRP Journal of Manufacturing Science and Technology, http://dx.doi.org/10.1016,/ j.cirpj.2014.10.001

[6] Rathi, V. dan Hunny, 2015, Analyzing the Effect of Parameters on SMAW Process, International Journal of Emerging Research in Management \&Technology, Vol: 4(6), pp: 16 - 21.

[7] Hasrizam, W.S., 2015, "Effect of Welding Heat Input on Microstructure and Mechanical Properties at Coarse Grain Heat Affected Zone of ABS Grade A Steel," ARPN Journal vol.10.

[8] Mizhar, S., 2014, "Pengaruh Masukan Panas Terhadap Struktur Mikro, Kekerasan dan Ketangguhan pada Pengelasan SMAW dari Pipa Baja Diameter 2,5 Inchi, ” Jurnal dinamis, Vol. 2.

[9] Talabi, S.I., Owolabi, O.B., Adebisi, J.A., Yahaya, T., 2014, Effect of welding variables on mechanical properties of low carbon steel welded joint, Advances in Production Engineering \& Management, Vol: 9(4), pp: 181 - 186

[10] Trimble, D., O’Donnell, G. E., Monaghan, J. 2014 Characterisation of Tool Shape and Roational Speed For Increased Speed During Friction Stir Welding of AA2024-T3. India: Elsevier Ltd Ireland. 
[11] Sulardjaka, D.F. Fitriyana, A. Budiman, 2017, Kajian Kekuatan Tarik dan Struktur Mikro Hasil Pengelasan Shield Metal Arc Welding dan Friction Stir Welding Baja Karbon St 37, ROTASI - Vol. 19(4), pp: 193-200.

[12] A. Kumar, S.S. Gautam dan A. Kumar, 2014, Heat Input \& Joint Efficiency of Three Welding Processes Tig, Mig and Fsw using AA6061, Int. J. Mech. Eng. \& Rob. Res., pp: 89 - 94.

[13] Shahinfar, A., Eftekhar, A.H., dan Eskandari, H., 2015, "Microstructural Comparison of Friction Stir Weldment and Shielded Metal Arc Welding in API-X65 Pipe Line," Journal of Academic and Applied Studies, Vol: 5 pp.1-3.

[14] Sonawan, H. dan R. Suratman, 2003, "Pengantar untuk Memahami Proses Pengelasan Logam," Bandung: Alfabeta. 